\title{
Association of Cardiovascular Risk Factors in Hypertensive Subjects with Metabolic Syndrome Defined by Three Different Definitions
}

\author{
Shrestha $\mathrm{R}^{1}$, Jha $\mathrm{SC}^{2}$, Khanal $\mathrm{M}^{3}$, Gyawali $\mathrm{P}^{3}$, Yadar $\mathrm{BK}^{3}$, Jha $\mathrm{B}^{3}$ \\ ${ }^{1}$ Department of Biochemistry, Nepal Medical College, Kathmandu, Nepal ${ }^{2}$ Department of Medicine, Tribhuvan University \\ Teaching Hospital, Kathmandu, Nepal. ${ }^{3}$ Department of Biochemistry, Tribhuvan University Teaching Hospital, Kathmandu, \\ Nepal
}

\section{ABSTRACT}

Introduction: Different authorities have put forward their criteria to define metabolic syndrome (MetS). The aim of this study was to find the prevalence of MetS in hypertensive individuals by the available three different definitions from National Cholesterol Education Program (NCEP), International diabetes Federation (IDF) and $\mathrm{WHO}$ and their association with other cardiac risk factors.

Methods: After anthropometric measurements fasting blood was analyzed for glucose, lipids, high sensitivity C-reactive protein (hsCRP) and anti-oxidized LDL antibody in 150 hypertensive individuals. A ten-year coronary heart disease risk was predicted using the Framingham risk score (FRS).

Results: The prevalence of MetS was $54.7 \%$ by NCEP, $42.0 \%$ by IDF) and $18.7 \%$ by WHO. As many as $63.4 \%$ had MetS by any definition, while only $9.4 \%$ fulfilled all the criteria of the three definitions. The association of cardiac risk factors also varied according to the definition used. hsCRP was significantly elevated in MetS compared to non-MetS. Body mass index, waist circumference and HDL-C were associated in MetS defined by NCEP and IDF. FRS was higher in MetS defined by Adult Treatment Panel and WHO definitions. An increase in urine albumin and a decrease in eGFR were associated with MetS individuals defined by WHO only.

Conclusion: There is a wide variation in the prevalence of MetS and associated cardiac risk factors according to three different definitions used. The different cardiac risk factors among MetS also vary with the definitions used. However, hsCRP and emerging risk factor are significantly elevated in hypertensive individuals with MetS as defined by all definitions

Keywords: Cardiovascular risk factors, hypertension, metabolic syndrome

\section{INTRODUCTION}

The metabolic syndrome (MetS) is a cluster of metabolic abnormalities that predisposes an individual to a greater risk of developing type 2 diabetes $^{1}$ and cardiovascular disease (CVD)..$^{2,3}$ Asian countries, including Nepal, contribute to the highest proportion of CVD burden when

Correspondence:

Mr. Rojeet Shrestha,

Department of Biochemistry,

Nepal Medical College, Atterkhel, Jorpati, Kathmandu, PO Box 13344,

E-mail:- cl.bichem@gmail.com, Mob no: 9841385536 
compared with any other regions globally, and subjects with metabolic syndrome face a twofold increased risk of all-cause mortality and a two to threefold increased risk of cardiovascular mortality. ${ }^{4}$ The constellation of major risk factors, life-habit risk factors, and emerging risk factors constitutes MetS, that includes abdominal obesity, atherogenic dyslipidemia (elevated triglyceride, small LDL particles, low HDL cholesterol), raised blood pressure, insulin resistance (with or without glucose intolerance), and prothrombotic and proinflammatory states. Different authorities have put forward their criteria to define MetS. There is a paucity of data regarding the prevalence of MetS in both the general population and hypertensive subjects in this country. This study was designed to find the prevalence of MetS in hypertensive individuals by three different definitions and their association with other cardiac risk factors.

\section{METHODS}

A total of 150 hypertensive individuals $(71$ men and 79 women) of age between 30 to 74 years were recruited randomly from the medical OPD of the Tribhuvan University Teaching Hospital (TUTH). Hypertension was defined by either a blood pressure (BP) of $\geq 140 / 90 \mathrm{~mm} \mathrm{Hg}$ or under anti-hypertensive medication. Individuals with any chronic disease, pregnancy-induced hypertension and those using lipidlowering drugs were excluded from the study. The waist circumference (WC) was measured at the highest point of the iliac crest during minimal respiration. The weight and height were recorded for the calculation of the body mass index (BMI). Two readings of BP were measured using a sphygmomanometer in the seated position after a ten-minute rest period and the mean was used for analysis. A fasting blood sample was collected for the estimation of glucose, total cholesterol (TC), triglyceride (Tg), HDL-cholesterol (HDL-C), estimated GFR $(\mathrm{eGFR})^{5}$, uric acid, high sensitivity C-reactive protein (hsCRP) and anti-oxidized LDL antibody (oxLDL Ab). The albumin-creatinine ratio (ACR) was determined from urine samples. The colorimetric method was used for the estimation of glucose, TC, Tg, HDL, uric acid and creatinine, whereas hsCRP, oxLDL $A b$ and urine albumin were estimated by immunoassay. LDL-cholesterol was calculated using the Friedewald formula. ${ }^{6}$ Diabetic status was defined by the 2003 American Diabetes Association updated criteria ${ }^{7}$ diabetes mellitus (DM) present if the fasting blood glucose (FBG) is $\geq 7.0 \mathrm{mmol} / \mathrm{L}$ or if the participants are under treatment with insulin or oral hyperglycemic agents. The ten-year coronary heart disease risk was predicted using Framingham risk score (FRS) ${ }^{8}$ derived on the basis of age, diabetes, smoking, blood pressure, total cholesterol and LDL cholesterol, as predictors for evaluating the cardiovascular risk.
We used three different definitions to define MetS. On the basis of the National Cholesterol Education Program - Adult Treatment Panel-III (NCEP-ATPIII) ${ }^{9,10}$, participants who had three or more of the following criteria were defined as having the MetS: 1) abdominal obesity (WC $>102 \mathrm{~cm}$ in men and $>88 \mathrm{~cm}$ in women), 2) concentration of $\mathrm{Tg} \geq 1.7 \mathrm{mmol} / \mathrm{L}, 3$ ) concentration of HDL-C $<1.03 \mathrm{mmol} / \mathrm{L}$ in men and $<1.29 \mathrm{mmol} / \mathrm{L}$ in women, 4) systolic $\mathrm{BP} \geq 130 \mathrm{mmHg}$ or a diastolic $\mathrm{BP} \geq 85 \mathrm{~mm} \mathrm{Hg}$ ), and 5) $\mathrm{FBG} \geq 5.6 \mathrm{mmol} / \mathrm{L} .9,10$ According to the International diabetes Federation (IDF) definition ${ }^{11}$, MetS was defined if subjects have central adiposity plus two or more of the following four factors: 1) raised concentration of $\mathrm{Tg} \geq 1.7 \mathrm{mmol} / \mathrm{L}$; 2) reduced concentration of $\mathrm{HDL}-\mathrm{C}<1.03 \mathrm{mmol} / \mathrm{L}$ in men and $<1.29 \mathrm{mmol} / \mathrm{L}$ in women; 3) raised blood pressure: systolic BP $\geq 130 \mathrm{~mm} \mathrm{Hg}$ or diastolic $\mathrm{BP} \geq$ $85 \mathrm{mmHg}$; and 4) raised FBG $\geq 5.6 \mathrm{mmol} / \mathrm{L}$. Central obesity was considered to be present when WC $\geq 90$ $\mathrm{cm}$ for males and $\geq 80 \mathrm{~cm}$ for females. According to the WHO criteria $^{12}$, MetS was defined as the presence of impaired fasting glucose ( $\geq 6.1 \mathrm{mmol} / \mathrm{L}$ ) with at least 2 of the following risk factors: 1) obesity (BMI $\geq$ 30); 2) dyslipidemia (plasma Tg concentrations $\geq 1.7$ $\mathrm{mmol} / \mathrm{L}$ and/or HDL-C levels $<0.9 \mathrm{mmol} / \mathrm{L}$ for men and $<1.0 \mathrm{mmol} / \mathrm{L}$ for women); 3 ) hypertension ( $\geq 140 / 90$ $\mathrm{mm} \mathrm{Hg}$ ); and 4) microalbuminuria (urinary ACR $\geq 4.0$ $\mathrm{mg} / \mathrm{mmol}$ ).

Consent was taken from each patients before study and the study was approved by Institutional review board of TUTH. Data were analyzed using the statistical software package SPSS 11.5 for Windows (SPSS). Data were expressed as mean \pm standard error of mean (SEM) or as percentage frequency. The comparison of the mean between different groups was done by ANOVA. Associations of categorical data were tested by $x^{2}$ test. All the $\mathrm{p}$-value were two- tailed, and those $<0.05$ (95 $\% \mathrm{Cl}$ ) were considered statistically significant.

\section{RESULTS}

Out of the 150 hypertensive participants between the ages of 30 and 74 years (mean age of 50 years), 71 were men and 79 were women. The mean ( \pm SEM) age of men and women was $50.6 \pm 1.4$ and $49.3 \pm 1.2$ years respectively. There was no significant difference in the BMI between men and women; however, men had a slightly higher WC ( $<<0.05)$. There was no difference between men and women in other parameter except for uric acid, which was found to be higher in men ( $p<0.001)$. Twenty five $(16.6 \%)$ of the hypertensive subjects were diabetic.

The overall prevalence of MetS in our population was found to be $82(54.7 \%), 28(18.7 \%)$ and $63(42.0$ $\%)$ using the criteria of NCEP ATPIII, WHO and IDF 
respectively (Table 1). The gender wise prevalence of MetS is shown in Figure 1. Figure 2 illustrates the overlap between the different definitions of MetS in men, women and in the total. The proportion of subjects who fulfilled all three definitions was 14 (9.4 $\%)$. In addition, $18(12.0 \%)$ had MetS according to the NCEP ATPIII definition only. Three $(2.0 \%)$ had MetS according to WHO definition only and $10(6.7 \%)$ had MetS according to the IDF definition only.

Table 1. Prevalence of the components of metabolic syndrome by three definitions (NCEP-ATPIII, WHO and IDF)

\begin{tabular}{|c|c|c|c|}
\hline & $\begin{array}{l}\text { Male } \\
(\mathrm{N}=71) \\
\mathrm{n}(\%)\end{array}$ & $\begin{array}{l}\text { Female } \\
(\mathrm{N}=79) \\
\mathrm{n} \%)\end{array}$ & $\begin{array}{l}\text { Total } \\
(\mathrm{N}= \\
150) \\
\mathrm{n}(\%)\end{array}$ \\
\hline \multicolumn{4}{|l|}{ NCEP ATP III } \\
\hline One component & $10(14.1)$ & $8(10.1)$ & $18(12.0)$ \\
\hline Two components & $25(35.2)$ & $23(29.1)$ & $48(32.0)$ \\
\hline $\begin{array}{l}\text { Three } \\
\text { components }\end{array}$ & $23(32.4)$ & $24(30.4)$ & $47(31.3)$ \\
\hline Four components & 12 16.9)) & $20(25.3)$ & $32(21.3)$ \\
\hline Five components & $1(1.4)$ & $4(5.1)$ & $5(3.3)$ \\
\hline MetS & 35 (49.3) & $47(59.5)$ & $82(54.7)$ \\
\hline \multicolumn{4}{|l|}{ WHO } \\
\hline One component & $10(14.1)$ & $11(13.9)$ & $21(14.0)$ \\
\hline Two components & $30(42.3)$ & $33(41.8)$ & $63(42.0)$ \\
\hline $\begin{array}{l}\text { Three } \\
\text { components }\end{array}$ & $19(26.8)$ & $23(29.1)$ & $42(28.0)$ \\
\hline Four components & $12(16.9)$ & $9(11.4)$ & $21(14.0)$ \\
\hline Five components & $0(0.0)$ & $3(3.8)$ & $3(2.0)$ \\
\hline MetS & $12(16.9)$ & $16(20.3)$ & $28(18.7)$ \\
\hline \multicolumn{4}{|l|}{ IDF } \\
\hline One component & $11(15.5)$ & $4(5.1)$ & $15(10.0)$ \\
\hline Two components & $19(26.8)$ & $22(27.8)$ & $41(27.3)$ \\
\hline $\begin{array}{l}\text { Three } \\
\text { components }\end{array}$ & $18(25.4)$ & $28(35.4)$ & $46(30.7)$ \\
\hline Four components & $21(29.6)$ & $18(22.8)$ & $39(26.0)$ \\
\hline Five components & $2(2.8)$ & $7(8.9)$ & $9(6.0)$ \\
\hline MetS & $32(45.0)$ & $31(39.2)$ & $63(42.0)$ \\
\hline
\end{tabular}

The baseline characteristics of hypertensive subjects fulfilling the three definitions of MetS are shown in Table 2. Cardiac risk factors - BMI, WC, FBG, TC, Tg, HDL-C, hsCRP and FRS were significantly different
$(P<0.05)$ when comparing those with and without MetS by the NCEP ATPIII guideline. In addition to this, there was also significant increase in the uric acid level in MetS as defined by IDF. In contrast, there was no significant difference in the BMI and WC among MetS and without MetS as defined by the WHO definition. However, there was a significant increase in age and $A C R$, and decrease in eGFR among MetS defined by WHO $(p<0.05)$.

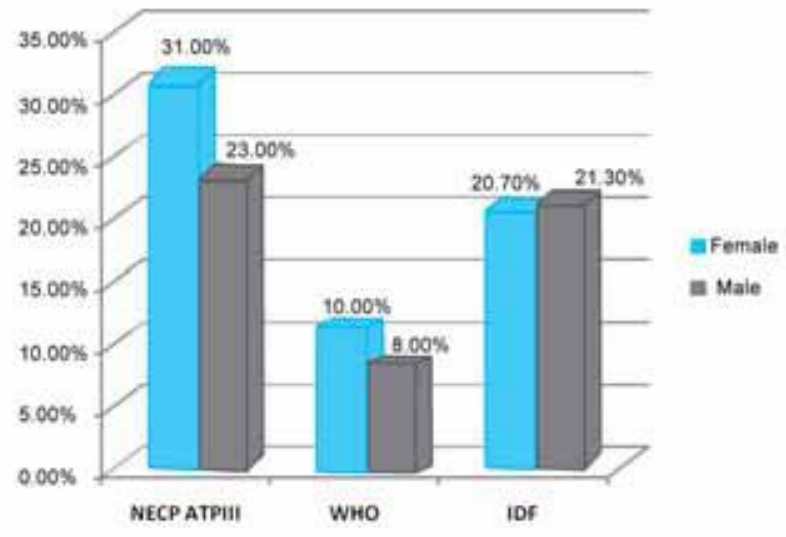

Figure 1: Gender wise prevalence of MetS, by three definitions (NCEP-ATPIII, WHO and IDF)

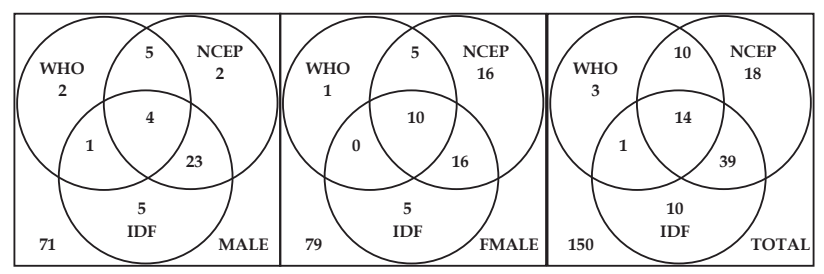

Figure 2: Prevalence of the metabolic syndrome (MetS) according to the three definitions used (NCEP ATPIII, WHO, IDF) in men, women and total.

The proportion of cases fulfilling each of the MetS criteria is presented in Table 3. Among MetS defined by the NCEP ATPIII, $82.9 \%$ and $81.7 \%$ had decreased HDL-C and increase $\mathrm{Tg}$ respectively. According to the WHO definition, $89.0 \%$ of MetS had dyslipidemia. $76.2 \%$ and $71.4 \%$ of MetS had a decrease in the $\mathrm{HDL}-\mathrm{C}$ and an increase the $\mathrm{Tg}$ respectively as defined by IDF (Table 3 ). The association of different grade of risk as indicated by the emerging risk factor - hsCRP and FRS among MetS by the three definitions is shown in Table 4. 
Shrestha. at.al Association of Cardiovascular Risk Factors in Hypertensive Subjects with Metabolic Syndrome ...

Table 2. Baseline characteristics in relation to the presence of the metabolic syndrome, by three definitions (NCEPATPIII, WHO and IDF)

\begin{tabular}{|c|c|c|c|c|c|c|}
\hline & \multicolumn{2}{|l|}{ NCEP ATP III } & \multicolumn{2}{|c|}{ WHO } & \multicolumn{2}{|c|}{ IDF } \\
\hline & No & Yes & No & Yes & No & Yes \\
\hline $\mathrm{N}$ & 68 & 82 & 122 & 28 & 87 & 63 \\
\hline Age (Years) & $48.5(1.3)$ & $51.2(1.3)$ & $48.8(1.0)$ & $55.2(1.9) \dagger$ & $49.1(1.2)$ & $51.3(1.4)$ \\
\hline Men (\%) & $36(52)$ & $35(43)$ & $59(48)$ & $12(43)$ & $39(45)$ & $32(51)$ \\
\hline Systolic BP (mm Hg) & $139.3(2.4)$ & $141.6(2)$ & $139.6(1.7)$ & $144.8(3.5)$ & $139.8(2.0)$ & $141.7(2.3)$ \\
\hline Dystolic BP (mm Hg) & $92.7(1.3)$ & $93.4(1)$ & $93.2(0.9)$ & $92.3(1.6)$ & $92.9(1.1)$ & $93.3(1.1)$ \\
\hline BMI (Kg/m2) & $24.0(0.4)$ & $27.1(0.6) \dagger$ & $25.7(0.4)$ & $25.7(0.8)$ & $23.4(0.5)$ & $28.8(0.4) \dagger$ \\
\hline WC, Men $(\mathrm{cm})$ & $81.8(1.41)$ & $91.5(1.2) \dagger$ & $87.36(1.2)$ & $83.0(2.2)$ & $80.3(1.2)$ & $94.2(0.7) \dagger$ \\
\hline WC, women $(\mathrm{cm})$ & 78.91 & $84.1(1.5) \dagger$ & $81.7(1.2)$ & $83.2(2.4)$ & $77.6(1.2)$ & $88.7(1.2) \dagger$ \\
\hline $\mathrm{FBG}(\mathrm{mmol} / \mathrm{L})$ & $4.8(0.1)$ & $5.8(0.2) \dagger$ & $4.8(0.1)$ & $7.9(0.4) \dagger$ & $5.2(0.1)$ & $5.6(0.3)$ \\
\hline eGFR (ml/min) & $78.7(2.3)$ & $77(2.6)$ & $80(1.9)$ & $68(3.9) \dagger$ & $74.8(2.2)$ & $81.8(3)$ \\
\hline Uric acid (mmol/L) & $329.8(10.8)$ & $357.2(11.8)$ & $342.5(8.4)$ & $354.9(24.3)$ & $330.6(10.9)$ & $\begin{array}{l}364.3 \\
(11.8) \dagger\end{array}$ \\
\hline Cholesterol (mmol/L) & $4.9(0.2)$ & $5.4(0.1) \dagger$ & $5.1(0.1)$ & $5.7(0.2) \dagger$ & $5.2(0.1)$ & $5.1(0.2)$ \\
\hline HDL-C (mmol/L) & $1.1(0.0)$ & $1(0.0) \dagger$ & $1(0.0)$ & $1(0.0)$ & $1.1(0.0)$ & $1(0.0) \dagger$ \\
\hline LDL-C (mmol/L) & $3.1(0.2)$ & $3.3(0.1)$ & $3.1(0.1)$ & $3.5(0.2)$ & $3.3(0.1)$ & $3.1(0.2)$ \\
\hline $\operatorname{Tg}(\mathrm{mmol} / \mathrm{L})$ & $1.4(0.1)$ & $2.4(0.2) \dagger$ & $1.8(0.1)$ & $2.4(0.2) \dagger$ & $1.8(0.1)$ & $2.2(0.2) \dagger$ \\
\hline $\mathrm{TC} / \mathrm{HDL}$ ratio & $4.6(0.2)$ & $6.2(0.3) \dagger$ & $5.3(0.2)$ & $6.2(0.5)$ & $5.2(0.2)$ & $5.8(0.3)$ \\
\hline Smoker (\%) & $13(19)$ & $13(19)$ & $21(17)$ & $5(18)$ & $12(14)$ & $14(22)$ \\
\hline Diabetic (\%) & $5(7.3)$ & $20(24.4)$ & $2(1.6)$ & $23(82.1) \dagger$ & $12(13.8)$ & $13(20.6)$ \\
\hline hsCRP (mg/L) & $2.9(0.5)$ & $6.5(0.9) \dagger$ & $4(0.5)$ & $8.7(1.8) \dagger$ & $4.0(0.6)$ & $7.1(1.3) \dagger$ \\
\hline oxLDL (U/L) & $38.7(3.1)$ & $44.9(2.7)$ & $40.4(2.2)$ & $49.3(5.6)$ & $41(2.9)$ & $43.6(2.7)$ \\
\hline $\mathrm{ACR}^{*}(\mathrm{mg} / \mathrm{mmol})$ & $6.4(1.3)$ & $7.1(1.4)$ & $5.3(0.8)$ & $13.4(3.6) \dagger$ & $6.9(1.2)$ & $6.7(1.6)$ \\
\hline FRS** & $10(0.9)$ & $17.2(1.5) \dagger$ & $11.4(0.8)$ & $24.9(3.0) \dagger$ & $13(1.2)$ & $15.3(1.6)$ \\
\hline
\end{tabular}

$+p<0.05$ (mean comparison between MetS and Non-MetS by ANOVA).

Values are means (SEM) or proportions (\%).

*Albumin Creatinine ratio, **Framingham Risk Score.

NCEP-ATPIII, National Cholesterol Education Program- Adult Treatment Panel III; WHO, World Health Organization; IDF, International Diabetes Federation. 
Shrestha. at.al Association of Cardiovascular Risk Factors in Hypertensive Subjects with Metabolic Syndrome ...

Table 3. Proportion of individuals with MetS (NCEP-ATPIII, WHO or IDF) fulfilling each criteria of the syndrome

\begin{tabular}{|c|c|c|c|}
\hline & NECP ATPIII & WHO & IDF \\
\hline MetS (n) & 82 & 28 & 63 \\
\hline \multicolumn{4}{|l|}{ MetS criteria: } \\
\hline Hypertension, n (\%) & $82(100)$ & $28(100)$ & $63(100)$ \\
\hline Hyperglycaemia, n (\%) & $30(36.6)$ & $24(85.7)$ & $16(25.4)$ \\
\hline Low HDL cholesterol, n (\%) & $68(82.9)$ & $15(53.6)^{*}$ & $48(76.2)$ \\
\hline Hypertriglyceridaemia, n (\%) & $67(81.7)$ & $20(71.4)^{*}$ & $45(71.4)$ \\
\hline Waist increased, n (\%) & $34(41.5)$ & - & $63(100)$ \\
\hline $\mathrm{BMI}$ increased, $\mathrm{n}(\%)$ & - & $5(17.9)$ & - \\
\hline Increased ACR, n (\%) & - & $22(78.6)$ & - \\
\hline Total HTN Subjects (N) & 150 & 150 & 150 \\
\hline \multicolumn{4}{|l|}{ MetS criteria: } \\
\hline Hypertension, n (\%) & $150(100)$ & $150(100)$ & $150(100)$ \\
\hline Hyperglycaemia, n (\%) & $33(22.0)$ & $26(17.3)$ & $33(22)$ \\
\hline Low HDL cholesterol, n (\%) & $95(63.3)$ & $61(40.7)$ & 95 (63.3) \\
\hline Hypertriglyceridaemia, n (\%) & $79(52.7)$ & $79(52.7)$ & $79(52.7)$ \\
\hline Waist increased, n (\%) & $41(27.3)$ & - & $75(50)$ \\
\hline BMI increased, n (\%) & - & $23(15.3)$ & - \\
\hline Increased ACR, n (\%) & - & $71(47.3)$ & - \\
\hline
\end{tabular}

The definitions of risk factors vary between the definitions of the MetS. *According to WHO, $89 \%$ of MetS had dyslipidaemia, $71.4 \%$ had triglycerides $>1.7 \mathrm{mmol} / \mathrm{l}$ and $53.6 \%$ had low HDL cholesterol (men $<0.9$ $\mathrm{mmol} / \mathrm{l}$, women < 1.0).

Table 4. Association of the grade of risk according to hsCRP and FRS among Mets by the three definitions

\begin{tabular}{|c|c|c|c|c|c|c|}
\hline & \multicolumn{2}{|c|}{ NCEP ATP III } & \multicolumn{2}{|c|}{ WHO } & \multicolumn{2}{|c|}{$\underline{\text { IDF }}$} \\
\hline & Non MetS & MetS & Non MetS & MetS & Non MetS & MetS \\
\hline & $(n=68)$ & ln $=82$ & $(n=122)$ & $(n=28)$ & $(n=87)$ & $(n=63)$ \\
\hline \multicolumn{7}{|l|}{$\underline{\mathrm{hsCRP}^{*}}$} \\
\hline Mild Risk & $28(41.1)$ & $17(20.7) \dagger$ & $40(32.8)$ & $5(17.8)$ & $31(35.6)$ & $14(22.2)$ \\
\hline Moderate Risk & $19(27.9)$ & $22(26.8)$ & $35(28.7)$ & $6(21.4)$ & $23(26.4)$ & $18(28.6)$ \\
\hline High Risk & $21(30.9)$ & $43(52.4)$ & $47(38.5)$ & $17(60.7)$ & 33 (37.9) & $31(49.2)$ \\
\hline \multicolumn{7}{|l|}{ FRS** } \\
\hline Mild Risk & $40(58.8)$ & $30(36.6) \dagger$ & $63(51.6)$ & $7(25.0) \dagger$ & $44(50.6)$ & $26(41.3)$ \\
\hline Moderate Risk & $23(33.8)$ & 27 (32.9) & $44(36.1)$ & $6(21.4)$ & $29(33.3)$ & 21 (33.3) \\
\hline High Risk & $5(7.3)$ & $25(30.5)$ & $15(12.3)$ & $15(53.6)$ & $14(16.1)$ & $16(25.4)$ \\
\hline
\end{tabular}

${ }^{*}$ hsCRP; Mild risk (< $\left.1.0 \mathrm{mg} / \mathrm{L}\right)$, Moderate risk $(1-3 \mathrm{mg} / \mathrm{L})$, High risk ( $\left.>3.0 \mathrm{mg} / \mathrm{L}\right){ }^{*}$ FRS; Mild risk $(<10$ $\%)$, Moderate risk (10-20\%), High risk ( $>20 \%)+p<0.05$ ( $x^{2}$-test) 
Shrestha. at.al Association of Cardiovascular Risk Factors in Hypertensive Subjects with Metabolic Syndrome ...

\section{DISCUSSION}

Identifying individuals at risk for the development of future coronary events is a critical issue in today's medical practice because it enables clinicians to decide which patients are eligible to receive evidence-based therapies that can prevent or delay the progression of atherosclerotic diseases. Assessment of presence of MetS is one of the clinically-reliable entities for predicting the risk for cardiac events. ${ }^{13}$ The NCEP ATP III had identified MetS as a secondary target of riskreduction therapy.

In this study, the prevalence of MetS in hypertensive subjects ranged from $18.7 \%$ to $54.7 \%$. The frequency of MetS in females was $59.5 \%, 20.3 \%$ and $39.2 \%$ versus $49.3 \%, 16.9 \%$ and $45.0 \%$ in men by ATP III, WHO and IDF respectively. As many as $63.4 \%$ had MetS by any definition, while only $9.4 \%$ fulfilled the criteria of all three definitions. Therefore, there is a great discrepancy in the prevalence of MetS in the same study population defined by the three different definitions, which can no doubt result in a dilemma for clinicians as to which definition to use. Though the components of MetS are almost similar in all definitions, this disparity results due to the use of different cut-off values of the components used to define MetS. We had the got highest prevalence of MetS using the definition by ATP III as it uses any three of the five components. Though the WC cut-off of the IDF is lower than that of ATP III, the higher prevalence using the ATP III definition is due to the mandatory criteria of the IDF definition for central obesity. The prevalence of MetS is least by the WHO definition because it requires the presence of impaired fasting glucose, and further, it has a higher cut-off value for FBG and FRS. Several other studies have also reported the low prevalence of MetS by the WHO definition compared to the ATP III and IDF. ${ }^{14,15}$ The worldwide prevalence of MetS ranges from $<10 \%$ to as much as $84 \%$, depending on age, region, urban or rural environment, ethnicity, and the definition of MetS used. ${ }^{16-18}$ To the best of our knowledge, this is the first study that has attempted, though in a small sample size, to find out the prevalence of MetS among hypertensive Nepalese. No national data are available for comparison so far. Most of our study population had dyslipidemia. Apart from mandatory component in each definition, the highest prevalence of metabolic risk factor is low HDL-C, which is similar to previous reports. ${ }^{19} 82.9 \%$ and $76.2 \%$ of MetS had low HDL-C as defined by ATP III and IDF respectively. In contrast, only $53.6 \%$ of MetS had reduced HDL-C as defined by WHO, which could be due to the lower cut-off value of HDL-C used by the WHO definition. The prevalence of hypertriglyceridemia is highest among MetS defined by ATP III (81.7\%).
This study showed significant difference in the BMI among MetS and non-MetS as defined by ATP III and IDF. Interestingly, though the WHO definition uses BMI as a component, its difference between MetS and nonMetS is insignificant. This could be due to fact that the WHO definition is primarily focused on impaired fasting glucose and central obesity is not mandatory. One of the advantage of the WHO definition is that it uses addition risk factors like urine albumin or ACR. In this study we found that $78.6 \%$ of MetS defined by WHO had elevated ACR. Further, there is significant decrease in eGFR in MetS compared to non-MetS individuals as defined by WHO. No such difference was seen among MetS defined by ATP III and IDF.

We found that hsCRP level is elevated among MetS compared to non-MetS defined by all three definitions $(p<0.05)$. Further, $52.4 \%, 60.7 \%$ and 49.2 $\%$ of MetS as defined by ATP III, WHO and IDF respectively had hsCRP concentration $>3.0 \mathrm{mg} / \mathrm{L}$. Several studies have shown that hsCRP is increased with elements of the MetS, such as hypertension ${ }^{20}$ and increased $\mathrm{BMI}^{21,22}$ and correlates with $\mathrm{Tg}$ and HDLcholesterol concentrations. ${ }^{23}$ Further, it has been shown that the risk of CVD doubles in MetS with hsCRP $>3.0$ $\mathrm{mg} / \mathrm{L}$ compared to those with MetS with hsCRP $<3.0$ $\mathrm{mg} / \mathrm{L} .{ }^{24}$ Since hsCRP is the established risk factors for coronary events, MetS with elevated hsCRP is a high risk for CVD. In this study, the ten-year predicted risk by FRS is correlated with MetS defined by ATP III and WHO. $30.5 \%$ and $53.6 \%$ of MetS defined by ATP III and $\mathrm{WHO}$ had FRS $>20 \%$ (high risk). However, only $25.4 \%$ of MetS defined by IDF had FRS > $20 \%$. In this study, one of the most important risk factors i.e., LDL-C, did not correlate with MetS defined by all three definitions, which is in agreement with the study of Schillaci et al. ${ }^{25}$ Therefore MetS itself is a poor indicator of absolute short-term risk as it does not contain key determinants of short-term risk, such as age, LDL-C gender, and smoking status. Therefore, MetS should not be used as a risk assessment tool to estimate shortterm risk. Finally, our study showed that the WHO definition is the best to recognize diabetes as $82.1 \%$ of MetS by the WHO definition were diabetic while only $24.4 \%$ and $20.6 \%$ of MetS defined by ATP III and IDF respectively were diabetic.

The small number of patients is the main limitation of this study. Since this study was carried in a single center, this cannot represent the Nepalese picture as a whole. Further studies with larger numbers of patients and in more centers would give the true scenario of the problem in Nepal. 


\section{CONCLUSIONS}

There is wide a variation in the prevalence of MetS among hypertensive individuals according to the different definitions used. Hypertension itself is an important risk factor for CVD and a number of other risk factors are associated with hypertension. Apart from the metabolic risk component used to define MetS the other risk factors like cholesterol and hsCRP were significantly elevated in MetS compared to non-MetS hypertensive individuals.

\section{REFERENCES}

1. Grundy SM, Hansen B, Smith SC Jr, Cleeman JI, Kahn RA; American Heart Association; National Heart, Lung, and Blood Institute; American Diabetes Association.Clinical management of metabolic syndrome: report of the American Heart Association/National Heart, Lung, and Blood Institute/ American Diabetes Association conference on scientific issues related to management. Circulation. 2004;109:551-6.

2. Lakka HM, Laaksonen DE, Lakka TA, Niskanen LK, Kumpusalo E, Tuomilehto J, et al. The metabolic syndrome and total and cardiovascular disease mortality in middle-aged men. JAMA. 2002;288:2709-16.

3. Isomaa B, Almgren P, Tuomi T, Forsén B, Lahti K, Nissén M, et al. Cardiovascular morbidity and mortality associated with the metabolic syndrome. Diabetes Care. 2001;24:683-9.

4. Ramaraj R, Chellappa P. Cardiovascular risk in South Asians. Postgrad Med J. 2008;84:518-23.

5. Cockcroft D, Gault MK. Prediction of creatinine clearance from serum creatinine. Nephron. 1976;16:31-41.

6. Friedewald WT, Levy RI, Fredrickson DS. Estimation of the concentration of low-density lipoprotein cholesterol in plasma without use of the preparative ultracentrifuge. Clin Chem. 1972;18:499-502.

7. The Expert Committee on the Diagnosis and Classification of Diabetes Mellitus: follow-up report on the diagnosis of diabetes mellitus. Diabetes Care. 2003;26:3160-7.

8. Wilson PW, D'Agostino RB, Levy D, Belanger AM, Silbershatz H, Kannel WB. Prediction of coronary heart disease using risk factor categories. Circulation. 1998;97:1837-47.

9. Expert Panel on Detection, Evaluation, and Treatment of High Blood Cholesterol in Adults. Executive summary of the third report of the National Cholesterol Education Program (NCEP) Expert Panel on detection, evaluation, and treatment of high blood cholesterol in adults (Adult Treatment Panel III). JAMA. 2001;285:2486-97.

10. Grundy SM, Brewer HB Jr, Cleeman JI, Smith SC Jr, Lenfant C. American Heart Association; National Heart, Lung, and Blood Institute. Definition of metabolic syndrome: Report of the National Heart, Lung, and Blood Institute/American Heart Association conference on scientific issues related to definition. Circulation. 2004;109:433-8.

11. Alberti KG, Zimmet P, Shaw J; IDF Epidemiology Task Force Consensus Group. The metabolic syndrome-a new worldwide definition. Lancet. 2005;366:1059-62.

12. Alberti KG, Zimmet PZ, WHO Consultation. Definition, diagnosis and classification of diabetes mellitus and its complications. Part 1: diagnosis and classification of diabetes mellitus. Provisional report of a WHO Consultation. Diabet Med. 1998;15:539-53.
13. Ninomiya JK, L'Italien G, Criqui MH, Whyte JL, Gamst A, Chen RS. Association of the metabolic syndrome with history of myocardial infarction and stroke in the Third National Health and Nutrition Examination Survey. Circulation. 2004;109:42-46.

14. Basit A, Shera AS. Prevalence of Metabolic Syndrome in Pakistan. Metab Syndr Relat Disord. 2008;6:171-5.

15. Lee CM, Huxley RR, Woodward M, Zimmet P, Shaw J, Cho $\mathrm{NH}$, et al. Comparisons of metabolic syndrome definitions in four populations of the Asia-Pacific region. Metab Syndr Relat Disord. 2008;6:37-46.

16. Desroches S, Lamarche B. The evolving definitions and increasing prevalence of the metabolic syndrome. Appl Physiol Nutr Metab. 2007;32:23-32.

17. Kolovou GD, Anagnostopoulou KK, Salpea KD, Mikhailidis DP. The prevalence of metabolic syndrome in various populations. Am J Med Sci. 2007,333:362-71

18. Procopiou M, Philippe J. The metabolic syndrome and type 2 diabetes: epidemiological figures and country specificities. Cerebrovasc Dis. 2005;20(Suppl 1):2-8.

19. Ruderman, N, Chisholm D, Pi-Sunyer X, Schneider S. The metabolically obese, normal-weight individual revisited. Diabetes. 1998;47:699-713.

20. Dodson PM, Shine B. Retinal vein occlusion: C-reactive protein and arterial hypertension. Acta Ophthalmol (Copenh). 1984;62:123-130

21. Haverkate F, Thompson SG, Pyke SD, Gallimore JR, Pepys MB. Production of C-reactive protein and risk of coronary events in stable and unstable angina. European Concerted Action on Thrombosis and Disabilities Angina Pectoris Study Group. Lancet. 1997;349:462-6.

22. Visser M, Bouter LM, McQuillan GM, Wener MH, Harris TB. Elevated C-reactive protein levels in overweight and obese adults. JAMA. 1999;282:2131-5.

23. Aronson D, Bartha P, Zinder O, Kerner A, Markiewicz W, Avizohar $\mathrm{O}$, et al. Obesity is the major determinant of elevated C-reactive protein in subjects with the metabolic syndrome. Int J Obes Relat Metab Disord. 2004;28:674-9.

24. Ridker PM, Buring JE, Cook NR, Rifai N. C-reactive protein, the metabolic syndrome, and risk of incident cardiovascular events: an 8-year follow-up of 14719 initially healthy American women. Circulation. 2003;107:391-7.

25. Schillac G, Pirro M, Vaudo G, Gemelli F, Marchesi S, Porcellati, et al. Prognostic value of the metabolic syndrome in essential hypertension. J Am Coll Cardiol. 2004;43;1817-22. 